\title{
Oeste Metropolitano do Rio de Janeiro: proposições, debates, desafios
}

Marcio Rufino Silva, Denise de Alcantara, Leandro Dias de Oliveira e André Santos da Rocha

\section{(2) OpenEdition \\ Journals}

Edição electrónica

URL: http://journals.openedition.org/espacoeconomia/16198

DOI: 10.4000/espacoeconomia.16198

ISSN: 2317-7837

Editora

Núcleo de Pesquisa Espaço \& Economia

Refêrencia eletrónica

Marcio Rufino Silva, Denise de Alcantara, Leandro Dias de Oliveira e André Santos da Rocha, «Oeste Metropolitano do Rio de Janeiro: proposições, debates, desafios », Espaço e Economia [Online], 19 | 2020, posto online no dia 01 setembro 2020, consultado o 24 setembro 2020. URL : http:// journals.openedition.org/espacoeconomia/16198; DOI : https://doi.org/10.4000/espacoeconomia. 16198

Este documento foi criado de forma automática no dia 24 setembro 2020.

(C) NUPEE 


\title{
Oeste Metropolitano do Rio de Janeiro: proposições, debates, desafios
}

\author{
Marcio Rufino Silva, Denise de Alcantara, Leandro Dias de Oliveira e André \\ Santos da Rocha
}

1 Nas últimas duas décadas, o estado do Rio de Janeiro viveu importantes mudanças urbanas, políticas, econômicas, culturais e ambientais no seu espaço metropolitano por meio da emersão de novas centralidades econômicas, industriais e logísticas. Tais transformações atingiram especialmente o Oeste Metropolitano do Rio de Janeiro que, mesmo com a crise de graves proporções que assolou o Brasil nos últimos anos e com o estado do Rio de Janeiro vivendo uma verdadeira "atmosfera de crise", permanece como importante recorte analítico para a reestruturação urbano-regional em curso.

Região, borda, extremo, porção, parte, segmento, fronteira, margem, limite, área: não faltam maneiras de se tratar este conjunto formado, integralmente ou parcialmente, pelas cidades situadas na parte oeste da Baixada Fluminense - Seropédica, Paracambi, Japeri, Queimados e Itaguaí; pela Zona Oeste da cidade do Rio de Janeiro, neste caso a Área de Planejamento 5, que corresponde a quase metade do território municipal ${ }^{1}$; e pelas partes periféricas do município de Nova Iguaçu. Espaço e Economia: Revista Brasileira de Geografia Econômica cumpre o relevante papel de fomentar o debate, apresentado nesse dossiê uma proposta analítica sobre este importante recorte da Região Metropolitana do Rio de Janeiro.

3 O Oeste Metropolitano do Rio de Janeiro dialoga, evidentemente, com outras propostas de regionalização. Além disto, conforme será demonstrado nos artigos a seguir, cruzando suas características histórico-geográficas - sobretudo aquelas que se referem aos padrões de desenvolvimento territorial - ao aporte dos investimentos públicos e privados, às práticas sociais derivadas de uma urbanização e metropolização que convive com traços de ruralidades resilientes, bem como à mobilização das formas da propriedade, temos um quadro que, segundo a premissa desse dossiê, permite individualizar esse recorte como, simultaneamente, uma região e um território. E é o 
seu movimento que compreendemos, hoje, como um norteador dos critérios principais a nos revelar essa realidade, que é de uma rica complexidade espaço-temporal.

4 Se a complexa noção de periferia metropolitana aparece como um corte analítico a subscrever a substância sócio-espacial dessa realidade regional, certamente a perspectiva de Oeste Metropolitano possibilita trazer, em nossa avaliação, novos elementos para uma problematização, em outros níveis, da relação entre centros e periferias, tanto na Região Metropolitana do Rio de Janeiro quanto nas demais metrópoles e regiões metropolitanas do Brasil e do mundo contemporâneo. É nesse sentido, inclusive, que a perspectiva espaço-temporal, quanto aos termos de uma situação geográfica, ilumina as estratégias do espaço, lidas e analisadas em várias das contribuições deste dossiê a partir da reestruturação territorial-produtiva, dos cenários de desenvolvimento urbano e periurbano, da mobilidade dos trabalhadores, da disposição dos resíduos sólidos, do dinamismo econômico, das questões do espaço rural, dos planos urbanos, da promoção imobiliária, do neodesenvolvimentismo e novos investimentos, dos impactos socioambientais, das zonas de sacrifício e dos movimentos insurgentes etc. $O$ múltiplo feixe de temáticas apresentadas nesse dossiê apenas ilumina questões prementes de uma região que, pouco a pouco, adquire novos contornos no escopo metropolitano do Rio de Janeiro e, ao mesmo tempo, apresenta questões paradigmáticas para o próprio processo de metropolização em outras escalas.

5 Se há uma justificativa histórica pela abrangência regional da bacia hidrográfica do Guandu, com a inequívoca relação de seus principais corpos hídricos, Rio Guandu e Aquífero Piranema, e da Baixada de Sepetiba, emergem, para além das riquezas hídricas e dos capitais em profusão, territórios periféricos com significativas similaridades com o "Sul" de Boaventura de Souza Santos ${ }^{2}$. Os moradores das periferias pobres das cidades; os trabalhadores informais e precarizados; as mulheres, que geram renda e acumulam os cuidados com família e casa; todos fazem parte desses coletivos sociais do Sul, tão presentes na região tornada uma zona de sacrifício $^{3}$. Se já padecem nos períodos que precedem as pandemias, são tais grupos periféricos que carregam o pesado ônus da atual pandemia global da covid-19, com serviços de saúde insuficientes e inadequados e sem contabilização confiável dos que sofrem com as contaminações. Os dois dossiês antecedentes a este publicados por Espaço e Economia: Revista Brasileira de Geografia Econômica [Números 18 e 19] apresentaram este importante debate sobre a pandemia e o cinismo e ganância corporativos e institucionais na realidade brasileira.

6 O Oeste Metropolitano configura-se como um extensivo laboratório do processo de metropolização e periferização, alavancados pelas desigualdades sócio-espaciais e por vulnerabilidades diversas, que ameaçam a justiça social e ambiental. $\mathrm{O}$ [ainda] rarefeito adensamento construtivo e populacional não os livra dos efeitos da urbanização dispersa, fragmentada e precária, ocasionadas pelas carências e mazelas de planejamento. De fato, encontram-se ameaçados pela expansão e ocupação desordenada e desprovida de qualidade socioambiental nos espaços livres de edificações municipais, públicos ou privados, de feições urbanas, periurbanas ou rurais. $O$ viés especulativo neoliberal atua sobre o uso e ocupação do solo e sobre o vasto estoque de terras não edificadas ou urbanizadas de forma predatória e injusta. Portos, indústrias e condomínios logísticos se sobrepõem às pré-existências e às ambiências, com impositivas e impactantes pegadas ecológicas. Há a supressão de atividades pesqueiras e agropastoris, expropriadas de seus territórios produtivos locais; a devastação de áreas vegetadas, bloqueando mananciais e corpos hídricos em prol da 
instalação de desproporcionais condomínios logísticos; e ainda a extração, por vezes ilegal, de recursos minerais, como areia e brita, com irreversíveis danos ambientais.

7 Apresentado sob distintos recortes e perspectivas nos artigos deste dossiê, o Oeste Metropolitano do Rio de Janeiro carecia de tratamento similar aos espaços luminosos do núcleo metropolitano. A então periferia da periferia vem, pouco a pouco, adquirindo luz própria, principalmente com a inserção de grandes projetos de investimentos, como a expansão do Porto de Itaguaí e a implantação do Arco Metropolitano, que, ao cruzar municípios e localidades dispersas e fragmentadas, não apenas amplia os pontos de conexão e visibilidade, mas representa um valioso filão na cadeia econômico-produtiva global. Tal luminosidade vem, entretanto, carregada do estigma de espaço periférico, de depósito ou despejo dos elementos indesejados no núcleo historicamente privilegiado. Seu caráter é o da extração, da exploração, do suprimento de recursos naturais e mãode-obra barata, sem considerar os impactos sócio-espaciais. A zona prioritária de instalação industrial concorre com os produtores de alimentos que tecem suas redes de resistência e sofrimento; se alinham aos insurgentes que sonham o território venturoso, saudável, próspero, pois conhecem seus caminhos, suas fontes e suas muitas potências.

O movimento irrequieto do social é, entretanto, estancado a cada passo; a marcha coletiva e voluntária interrompe-se, pelo medo, pela violência, pela brutalidade dos empreendimentos globais e mais fortes que os sonhos rebeldes. Quanto se torna notícia na mídia falada, escrita ou televisionada, ou nas redes sociais, o trágico, o fatídico, o sinistro, o brutal e a injustiça definem a linguagem jornalística. Ou seja, como verdadeiras zonas de sacrifício, os espaços do Oeste Metropolitano se tornam vítimas do progresso e da expansão da metrópole, com prejuízos ao meio ambiente, desinvestimento e usos do solo indesejáveis e atividades econômicas geradoras de impactos socioambientais os mais diversos, próximos a lugares habitados por populações desguarnecidas da proteção oficial do Estado, que favorece o capital e se alia à ação violenta de grupos paramilitares e do crime organizado. As histórias e registros oficiais ainda não dão conta da importância regional, das riquezas e potencialidades, das pré-existências, das territorialidades pujantes, dos movimentos sociais cujos gritos e desejos estão contidos em seus cantos e escondidos em seus recantos.

9 De modo algum, portanto, abrem-se loas a esse modelo de desenvolvimento econômico hegemonicamente pautado nos micro e macro investimentos presentes nessa região. Pelo contrário: os diversos artigos abrem diferentes flancos de uma perspectiva crítica ao saldo negativo de um verdadeiro processo predatório oriundo de uma economia que cresce ou se reproduz devastando ambientes e populações cada vez mais vulnerabilizadas, reproduzindo desigualdades e aprofundando segregações socioespaciais e injustiças ambientais. Um cruzamento necessário entre a ecologia política e a crítica da economia política do espaço ensaia-se, de certo modo, a partir desse conjunto.

Outrossim, o debate aqui proposto é duplamente fruto das transformações que vêm ocorrendo nesta porção da região metropolitana: se, por um lado, as materializações das novas dinâmicas econômicas em curso impulsionam mudanças sensíveis na paisagem econômica dessas cidades, de outro, a visibilidade, no campo acadêmico, só é possível diante da consolidação e expansão do ensino de universitário. Hoje há muitos grupos que estão localizados na periferia metropolitana, como unidades da 
Universidade do Estado do Rio de Janeiro (UERJ), da Fundação de Apoio à Escola Técnica (FAETEC), da Fundação Centro Universitário Estadual da Zona Oeste (UEZO) e da Universidade Federal Rural do Rio de Janeiro (UFRRJ), entre outras instituições de ensino e pesquisa, públicas e privadas, cujos trabalhos reverberam em qualidade analítica dos novos temas investigados.

11 Neste sentido, a Universidade Federal Rural do Rio de Janeiro (UFRRJ) possui papel primordial, com dois campi universitários localizados na periferia da região metropolitana - a saber, Seropédica e Nova Iguaçu -, somados à consolidação e crescimento de grupos de pesquisa e programas de pós-graduação das áreas de Ciências Humanas e Ciências Sociais Aplicadas. Nomeadamente, aqui neste dossiê, há forte presença das áreas de Geografia, do Planejamento Urbano e da Economia Regional, por meio dos programas de pós-graduação em Geografia (PPGGEO-UFRRJ) e em Desenvolvimento Territorial e Políticas Públicas (PPGDT-UFRRJ). As pesquisas, outrora peremptoriamente invisibilizadas, se tornaram mais potentes mediante as próprias demandas de pesquisadores e estudantes em buscarem interpretações acerca de questões relativas aos seus espaços de vivências e seus territórios de circulação. Também é necessário considerar que o desenvolvimento destas pesquisas está alinhado ao comprometimento de tais pesquisadores como intelectuais orgânicos, que retornam para seus espaços o conhecimento desenvolvido no âmbito universitário materializado não somente em formato de artigos, livros e teses, mas também nos ambientes de compartilhamento vivenciados em muitos eventos sobre esses municípios e nas inúmeras atividades de extensão.

Este dossiê, em seus múltiplos tensionamentos teóricos-interpretativos, é também uma forma de deixar o subalterno falar. É, portanto, uma forma de apresentar a metrópole tendo a periferia como centralidade. Um espaço opaco que agora se revela iluminado, não apenas pelas racionalidades logístico-industriais que o inclui de forma precária à sua dinâmica produtiva, mas porque há uma reflexão intensa acumulada em cerca de dez anos de reflexão coletiva, na qual alunos-professores-pesquisadores-moradores puderam construir suas próprias demandas de investigação, de forma dialógica e não hierárquica com suas realidades.

\section{NOTAS}

1. A AP5 é formada pelos bairros cariocas de Deodoro, Vila Militar, Campo dos Afonsos, Jardim Sulacap, Magalhães Bastos, Realengo, Padre Miguel, Bangu, Gericinó, Senador Camará, Santíssimo, Campo Grande, Senador Vasconcelos, Inhoaíba, Cosmos, Paciência, Santa Cruz, Sepetiba, Guaratiba, Barra de Guaratiba, Vila Kennedy e Pedra de Guaratiba.

2. SOUZA SANTOS, B. Para além do pensamento abissal: das linhas globais a uma ecologia dos saberes. In: SANTOS, B. S.; MENESES, M. P. Epistemologias do Sul. São Paulo: Cortez, 2010, p. 31-83.

3. ACSELRAD, Henri. Conflitos Ambientais no Brasil. Rio de Janeiro: Relume Dumará, 2004. 


\section{AUTORES}

\section{MARCIO RUFINO SILVA}

Mestre e Doutor em Geografia Humana pela Universidade de São Paulo (USP). Professor Permanente do Programa de Pós-Graduação em Geografia (PPGGEO) e Associado do Programa de Pós-Graduação em Desenvolvimento Territorial e Políticas Públicas (PPGDT) da Universidade Federal Rural do Rio de Janeiro. Professor Adjunto do Curso de Geografia (Bacharelado e Licenciatura) da UFRRJ, campus Seropédica. Coordenador do grupo de pesquisa "Para uma crítica da Economia Política do Espaço" (UFRRJ) e pesquisador do grupo "Geografia urbana: a vida cotidiana e o urbano" (USP). ORCID: https://orcid.org/0000-0002-0301-1325. E-mail: marciorufis@gmail.br.

\section{DENISE DE ALCANTARA}

Professora do Departamento de Arquitetura e Urbanismo e do Programa de Pós-Graduação em Desenvolvimento Territorial e Políticas Públicas e Pesquisadora Líder do Grupo GEDUR, da Universidade Federal Rural do Rio de Janeiro, Pesquisadora Colaboradora do Grupo Lugares e Paisagens, da Universidade Federal do Rio de Janeiro, Pesquisadora Visitante do Behner Stiefel Center for Brazilian Studies da San Diego State University; Mestre e Doutora pelo PROARQ-UFRJ e Bolsista de Produtividade JCNE-FAPERJ com a pesquisa Territórios e Paisagens Perimetropolitanos: conflitos e desigualdades sócio-espaciais e cenários prospectivos no Rio de Janeiro na perspectiva da Nova Agenda Urbana 2030. ORCID: https://orcid.org/ 0000-0002-6482-0943. E-mail: denisedealcantara@gmail.com.

\section{LEANDRO DIAS DE OLIVEIRA}

Professor Associado do Departamento de Geografia (DGG-IA) da Universidade Federal Rural do Rio de Janeiro na área de Geografia Econômica e da Indústria. Licenciado e Mestre em Geografia pela UERJ - Universidade do Estado do Rio de Janeiro, Doutor em Geografia pela UNICAMP Universidade Estadual de Campinas e Pós-doutor em Políticas Públicas e Formação Humana da Universidade do Estado do Rio de Janeiro (PPFH-UERJ). Professor dos quadros permanentes do Programa de Pós-Graduação em Geografia (PPGGEO-UFRRJ) e do Programa de Pós-Graduação Interdisciplinar em Humanidades Digitais (PPGIHD-UFRRJ). Coordenador do Laboratório de Geografia Econômica e Política, atuando na linha Reestruturação Econômica-Espacial Contemporânea (REEC-LAGEP). Membro da ReLAEE - Rede Latino-Americana Espaço e Economia. Orcid: https://orcid.org/0000-0001-7257-0545. Página eletrônica: r1.ufrrj.br/geografiaeconomica. E-mail: ldiasufrrj@gmail.com.

\section{ANDRÉ SANTOS DA ROCHA}

Professor Adjunto do Departamento de Geografia e do Programa de Pós-graduação em Geografia da Universidade Federal Rural do Rio de Janeiro. Doutorado em Geografia pela Universidade Federal do Rio de Janeiro). Coordenador do Laboratório de Geografia Econômica e Política LAGEP. Orcid: https://orcid.org/0000-0003-0547-5550. E-mail: asrgeo@gmail.com. 